\title{
The Invisible Around: Art And Informational Space [The Unstable Place]
}

\section{SIGRADI2018 TECHNOPOLITICAS \\ xxii congresso da sociedade iberoamericana de gráfica digital 22th conference of the iberoamerican society of digital graphics 07|08|09|novembro|2018 iau usp | são carlos | sp br}

\author{
Lucas Bambozzi \\ LabOUTROS FAUUSP | Brazil | Ibambozzi@usp.br
}

\begin{abstract}
The paper discusses variants of informational spaces, permeated by connectivity and communication flow. The approach considers the 'place' as a field of semantic migrations, it seeks to investigate an architectural space that tends to include invisible aspects in its constitution, affected by a set of recent communication technologies. It comments on creative processes and artistic experiments investigating ways to "see" or visualize electromagnetic fields, radio waves, wi-fi and cellular signals generated by media in circulation spaces, in convergences of crossing signs and systems.
\end{abstract}

Keywords: Informational space; Electromagnetic fields; Obsolescence; Mobility; Context specificity.

\section{INTRODUÇÃO}

O artigo analisa as transformações recentes da noção de 'lugar' diante da emergência dos espaços informacionais, em sociedades permeadas por conectividade, fluxos distintos de comunicação e serviços em redes tecnológicas. A pesquisa vem sendo realizada a partir da observação de novas especificidades de um espaço arquitetônico que inclui cada vez mais aspectos imateriais em sua constituição, como campos de radiofrequência (RF) e ondas eletromagnéticas (EMF) gerados por celulares, redes wi-fi, transmissões de TV, satélites e telefones sem fio. Tal contexto é tema ou objeto de discussão de uma arte em constante atrito com elementos da comunicação, em relações que se intensificaram notavelmente nos últimos 30 anos. As investigações buscam apontar formas e recursos que permitam fazer ver seus componentes intrínsecos e politizar a sua constituição e não apenas comprovar o quanto o espaço pode ser de fato considerado pelo que não é visível. O espaço passa a ser rediscutido a partir de novas camadas e especificidades, sendo considerado tanto pelos elementos visíveis como pelos que não se podem ver - elementos que ganham forma e corpo a partir de recursos discursivos, técnicas de medição e formas criativas de percepção de suas qualidades.

Buscando demonstrar e localizar esses aspectos dentro de um ponto de vista discursivo, o projeto parte inicialmente de considerações metafóricas para se apoiar em conceitos teóricos que discutem três abordagens essenciais à pesquisa: os lugares carregados de informação; as tecnologias, suas instabilidades e os fluxos de comunicação gerados por sistemas atuais; as artes criadas para lugares específicos e como elas podem gerar formas de sensibilização e pensamento crítico.

\section{METODOLOGIA}

Como forma de abordar metodologicamente cada um desses aspectos a pesquisa se vale de autores que discorrem sobre conceitos-chave dentro desse universo: o espaço informacional e as formas de comunicação imersas na sociedade (Castells, Virilio, Flusser, DidiHuberman, Greenfield, Stalder); a noção do lugar e espaço na arquitetura e na arte (Foster, Lippard, Crimp, Kwon, Meyer); questões ligadas à imaterialidade (Cauquelin, Bourriaud, Latour); as políticas associadas ao corpo, produção de subjetividade e produção simbólica em espaços compartilhados (Foucault, Pelbart, Ranciére, Lazzarato, Deutsche, Bishop). Em diálogo com a abordagem filosófica, a metodologia envolve também uma série de obras e artistas que convergem esses conceitos em trabalhos que são tanto alusivos a dúvidas acerca dos constituintes do espaço como indutores de conscientização a respeito das invisibilidades, ideologias e políticas imersas em espaços de circulação e convívio coletivo. Assim, além dos autores citados, as fontes incluem também tópicos temáticos em listas de discussão específicas como Nettime, Empyre ou NetBehaviour, documentários como Resonance: Beings of Frequency (2012), Lo And Behold: Reveries of the Connected World (2016), Dark Net (2016) e outros, além de projetos de arte desenvolvidos pelo pesquisador e por vários artistas nacionais e internacionais.

\section{RESULTADOS}

Há cada vez mais formas de se aferir uma maior percepção dos fluxos de comunicação e campos eletromagnéticos cada vez mais ubíquos, senão intrusivos e determinantes de nossa participação e existência, nas esferas sociais e culturais em nosso entorno. A discussão associada a práticas artísticas e direcionada ao pensamento crítico busca assim questionar o quanto a constituição aparentemente 
imaterial e por vezes invisível da informação ao nosso redor pode engendrar a possibilidade de desvelar novas perspectivas de atuação política e social através das mídias.

O aprofundamento nas questões apresentadas vem produzindo contribuições nas áreas da arquitetura, planejamento urbano, comunicação e arte, bem como em campos correlatos de conhecimento.

\section{DISCUSSÃO}

Considera-se uma suposta desmaterialização da noção de lugar a partir dos anos 1970, quando os circuitos passam a incorporar obras onde "o mapeamento sociológico é explícito", como definido por Hal Foster em O retorno do real (1996). Ao observar a prática de artistas como SSMichael As Asher, is uma definição de site que inclui também uma série de operações ocultas, como por exemplo a "is inestrutura is (1999)

Em função da ampliação do debate em torno das qualidades e diferentes noções do lugar, o site passa a não ser mais estritamente físico, mas incorporado de um sentido discursivo e social, a ser decodificado em suas qualidades constituintes. O que parece não estar sendo devidamente enfrentado é o da especificidade de um contexto permeado agora por novos fluxos de comunicação, nem sempre visíveis ao redor.

Falemos então de sistemas que flertam com a arte a partir da ótica da comunicação, e se intrometem em áreas da arquitetura. Trata-se de um constituinte do espaço que não molda diretamente a paisagem mas o próprio olhar, borrando a nitidez dos detalhes, ou se infiltrando na percepção feito zumbido em frequência indistinguível atuante no espaço, "presente" por assim dizer.

Mas ao invés de nos adentrarmos em digressões técnicas da comunicação envolvendo sinal e ruído, a proposta aqui é abordar elementos do entorno que se revelam como aparição, como componentes de um espaço habitado por intervenções de natureza nem sempre conhecida.

Hannah Arendt nos indica como juntar coisas aparentemente distintas ao discorrer sobre as coisas que tem a qualidade de 'aparecer', em sua crítica ao pensamento metafísico em A Vida do Espírito (1991). Segundo Arendt, o erro e a ilusão são inerentes às práticas tanto do cientista como do filósofo, e nada escapa a uma renovação da ideia de aparência, enfatizando o valor da superfície - e o que escapa da (mera) aparência. Trata-se de um pensamento aprofundado sobre o querer, o pensar, o julgar e outras capacidades intelectuais da mente (traduzido como espírito para evitar aproximações com positivismos ou mentalismos vulgares, segundo notas da tradução) através do qual a autora define a própria política da esfera pública, como "o espaço da aparição".

Rosalyn Deutsche, em seu artigo "A arte de ser testemunha na na esfera pública dos tempos de Guerra", sobre a obra "Projeção Hiroshima" de Krzysztof Wodiczko, retoma o pensamento de Arendt, comentando que, ao enfatizar aparição, a autora estreita as relações entre a noção de esfera pública e a visão, abrindo, "sem saber, a possibilidade para que as artes visuais possam ter um papel no aprofundamento e expansão da democracia."

Este artigo de Deutsche aborda o papel que artistas contemporâneos (no caso do artigo, Wodiczko), desempenham no sentido de revelar ou tornar visível a participação de segmentos da sociedade apagados ou relevados ao esquecimento. É uma posição que se refere não exatamente a uma forma metafísica, mas à alteridade, que nos diz da aparição do outro, "questão que é da ética e política do viver juntos num espaço heterogêneo." (2009).

Deutsche sugere que trabalhos como o de Wodiczko buscam estender a esfera pública, possibilitando àqueles que foram tornados invisíveis, "fazer sua aparição". Naturalmente esse processo envolve a conclamação de um espectador disposto a responder a essa aparição, como uma capacidade de visão a ser exercitada.

Em Projeção Hiroshima, realizada no Japão em 1999, Wodiczko deu a um prédio traumatizado pelos horrores da guerra o status de sujeito falante, resgatando-o de sua condição muda. Em The Homeless Projection, o trabalho estimula uma leitura pública permeada pela agressividade com que as ações de renovação do de uma área pública embelezada pela lógica da especulação urbana esconde e omite as contradições da história e dos excluídos.

Essas e outras projeções em grande escala de Wodiczko dão visibilidade a certos assombros sociais. Ao enfatizar a ausência, elas também nos pontuam o quanto a informação imaterial pode estruturar o espaço público de forma tão potente como o a arquitetura construída fisicamente -- inclusive em termos de construção de um espaço comum que valoriza o outro como elo fundamental desse ambiente compartilhado.

São trabalhos que se adentram também no político de forma direta, nos sugerindo um estado híbrido, em uma presença imaterial, que se torna potente ao ir de encontro à fisicalidade de espaços de circulação. Os projetos de vídeo de Dan Graham relacionados à arquitetura (desenhados para interação social em espaços públicos) também foram marcos no que se refere a um entrelaçamento entre o social, o espaço arquitetônico e a imaterialidade das imagens. 
Walter de Maria, em O Campo de Raios (1977) cria uma obra de grandes proporções, com 400 postes de aço inoxidável, cuja forma só pode ser percebida do alto, em sobrevoo pela região desértica do Novo México nos EUA. $A$ incidência de raios não é frequente como se poderia supor, e os visitantes que se aventuram a conhecer a obra in loco geralmente identificam qualidades outras, "que não podem ser capturadas por fotografias ou descrições" (GIBSON, 2004) mas por experiências sensoriais ao longo das diferentes fases do dia. Interessa aqui o quanto a obra preenche o vasto espaço de suposições e expectativas - para além dos fenômenos naturais suscitados.

São trabalhos e projetos que talvez façam ecoar o pensamento de Bachelard: "a imaginação aumenta os valores da realidade" (1989 p. 219), sugerindo que a imaginação funciona como disparador de estímulos aos aspectos não revelados de um lugar.

\section{ESTRATÉGIA REVERSA: ANTEVER PARA ENTENDER}

"O que se vê provém do que não é aparente". A partir dessa frase de Paulo de Tarso, mais conhecido como o apóstolo São Paulo, Paul Virilio comenta em O Espaço Crítico o quanto a característica imaterial das formas televisivas, tão emergentes a partir dos anos 1980, reafirmam aspectos da metafísica. Se o que se vê não é aparente há um questionamento "não apenas da visibilidade como fundamento da credulidade ocular ou ótica, mas como validade moral, ética e científica" (Virilio, 1993, p. 57). Uma questão similar já se sobressaía com o debate teológico sobre o telescópio de Galileu: "pode-se afirmar que se assistiu realmente a uma missa através de uma luneta?" (1993, p. 60)

Trata-se porém de se fazer ver, uma vez mais, "tornar visível", em formas de detecção de presenças, num sentido que oscila, não exatamente no campo metafísico, mas de produção simbólica, que tangencia o poético talvez.

Exemplos dessa conjugação entre componentes antes vistos tão separadamente, entre campos muito distintos, vem se somando aos poucos e desenhando o que poderia ser considerada uma política da visibilidade, onde busca-se entender o invisível para que se possa viabilizar aparições, seja para que tenham voz e presença, seja para que possamos reagir ou negociar com os contextos que as geram.

Se a relativização da visibilidade apoiada em projeções é uma qualidade típica de trabalhos que lidam com a luz, a alegoria da Caverna de Platão seria um exemplo ancestral de uma fantasmagoria bastante convincente. Mas para um maior delineamento das políticas de visibilidade mais atuais, que envolvem camadas de informação mais complexas, talvez seja necessário ir além das situações projetivas, envolvendo a necessidade de detectar o que as camadas invisíveis representam politicamente - quando não promovem a emergência de questões sociais.

Tomemos a cidade como indutora de especificidades que fogem ao espectro da visão. A avenida Paulista por

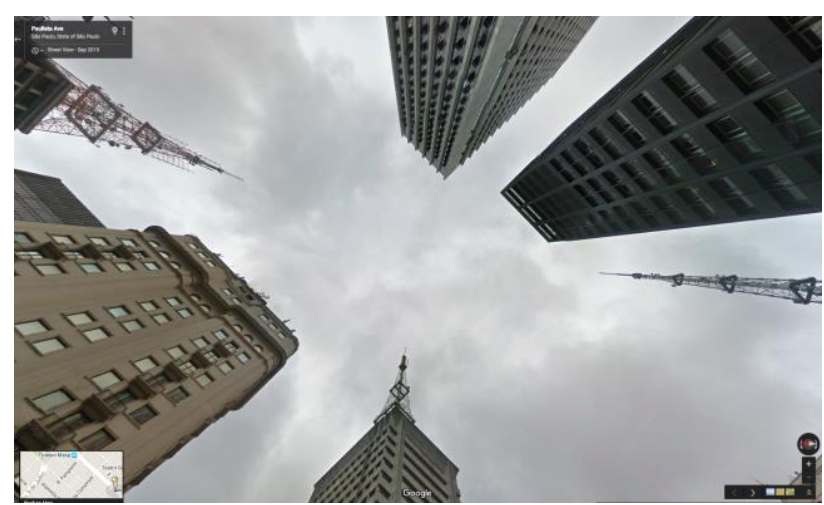

Figura 1: Visão da Avenida Paulista onde aparecem 3

antenas de TV - Google street view [http://bit.ly/1ktxS7s]

exemplo, em sua paisagem mais imediata, representa tipicamente um tipo de poder centrado no mercado financeiro, abrigando ainda inúmeras agencias e sedes bancárias - poderio que vem migrando, desde os anos 80 para a avenida Luis Carlos Berrini. Mas curiosamente, é acima do nível da avenida, situada na topografia mais alta da cidade, que vemos uma outra camada da paisagem, dominada pelo poder das comunicações, que se faz notar tanto em sua imagem mais aparente, seja nos cartões postais que exibem as principais torres de transmissão de TV da cidade, seja na sua parte "invisível": as interferências causadas pela maior concentração de poluição derivada de campos eletromagnéticos até hoje já medida em um centro urbano no Brasil, e talvez no mundo.

Na região estão mais de 35 estações de rádio e TV segundo a Anatel, em dados que se repetem desde 2006. A recente proliferação das antenas emissoras de sinal de celular também tira vantagem da topografia, formam uma nova camada intersticial de emissão de campos eletromagnéticos, em uma nova faixa de onda, situada no topo de muitos prédios entre 10 e 20 andares, tanto residenciais como comerciais, em um desenho de paisagem que remete mais às periferias do que a um centro econômico. Trata-se de uma densidade de sinais de fato crítica na região, constituída por amplo espectro de frequências, diferentes potências de sinais e gerações de tecnologias (equipamentos mais antigos, não otimizados, tendem a demandar maior potência), o que se soma a antenas emissoras e receptoras de internet via rádio e à pesada infra-estrutura de conectividade necessária para a operação de escritórios, residências, agências bancárias gigantes, hotéis, hospitais e centros comerciais, em sistemas de menor escala mas em vasta quantidade.

Com isso considera-se a avenida uma zona crítica e emblemática, onde fantasia, mito, ciência e geopolítica se misturam, em uma espécie de triângulo das bermudas: carros com circuitos eletrônicos falham, teclados musicais captam vozes de rádio, hospitais necessitam blindagens em salas de cirurgia, aparelhos elétricos são danificados sem motivo aparente, certas aves perdem sua orientação de vôo, algumas pessoas se sentem mal, além de muitas outras fantasmagorias relatadas com frequência. Ou seja, a associação da avenida a campos eletromagnéticos enigmáticos é tão evidente que ela se constitui também como um local afetado política e socialmente pelo que não se vê, estando imersa em um nuvem de poluição eletrônica (invisible smog). Isso não constitui novidade 
para os moradores que passam a considerar essa estranha especificidade, em seu dia-a-dia. A avenida Paulista tem as especificidades conhecidas de uma obra, não de arte, claro, mas de uma confluência arquitetônica que inclui o invisível como parte de sua constituição.

Se na análise de Rosalyn Deutsche a aparição se dá a partir de um outro excluído da sociedade, aqui é todo um poderio econômico que se emerge, de forma totalitária, fazendo representar tanto o executivo como o precariado que opera a partir do trabalho imaterial, alheios e ignorantes da sua exploração pelo capital cognitivo, que lança seus tentáculos pela conectividade em tempo integral, sem trégua.

Novos assombros, novos incômodos surgem a partir de sistemas pervasivos e ubíquos, muitas vezes de funcionamento errático ou ligados a finalidades capciosas, aumentando genericamente as malvadezas dos pacotes de tecnologias que nos vendem em nome do progresso ou das cidades inteligentes.

Nesse campo sempre surgem mais perguntas que respostas: "Como ver, apreender, narrar essas máquinas que nos fazem visíveis e que no entanto escapam à nossa percepção e ação?" indaga Fernanda Bruno (2015) a respeito dos dados que se intrometem ao nosso redor, em máquinas que sabem muito de nós e pouco sabemos delas. "Como negociar com elas, como contestá-las, contrariá-las e eventualmente sabotá-las?", continua Bruno.

Em uma série de projetos ligados a minha prática artística, busco uma aproximação entre sistemas físicos, sua presença material e sistemas de comunicação que envolvem fluxos imateriais, apontando as especificidades, tensões e conflitos advindas desse cruzamento.

São formas de visualização de informação que podem se dar pela geolocalização, pelo acesso a uma rede ou por distúrbios causados em sensores ou mesmo corpos presentes num determinado ambiente.

A perspectiva de visualização de campos eletromagnéticos (EMF) por exemplo é uma das buscas recentes em trabalhos de minha autoria como no projeto "Das coisas quebradas" (2012). O projeto converte o espaço informacional que nos rodeia em um sistema "objetificado", que representa um processo geralmente invisível. A máquina tem como input as variações de leitura dos sinais que circulam no espaço aéreo (sinais de Radiofrequencia RF, ou campos/ondas conhecidas como Extreme Low Frequency ELF ou Electric Magnetic Fields EMF), cuja saturação em determinados ambientes pode ser preocupante em vários aspectos.

A partir desses dados, o sistema se acelera e executa movimentos em uma máquina que culminam com uma ação destrutiva dos aparelhos celulares estocados (ou dispensados pelo usuário), o que para muitos pode representar uma espécie de acerto de contas com o consumismo associado às tecnologias que observamos hoje. Junto ao mecanismo de destruição da máquina, um monitor LCD mostra um gráfico que informa ao público a interação que ocorre no sistema: informações relativas à leitura da densidade da potência no ambiente (milliwatts por metro quadrado - mw/m2) são escritas na tela, nos permitindo deduzir o que acontece entre as medições e o funcionamento da máquina. Através desse componente digital da máquina, podemos saber por exemplo, qual foi o pico dos sinais nos últimos minutos, o momento em que o sistema iniciou as operações e há quanto tempo está em funcionamento. Esses e outros dados tornam visíveis informações que geralmente nos são omitidas.

Em seu conjunto de relações, o projeto sugere a abertura de sistemas fechados, em alusão ao "clareamento" das caixas pretas, apontado por Vilem Flusser (1985). Potencialmente, podem também permitir o pensamento crítico a partir de uma condição onde todos são veem responsáveis pela que ocorre nos espaços de circulação pública. Seu funcionamento leva em consideração um fluxo de informação que é produzido coletivamente, em interações entre o público e o sistema.

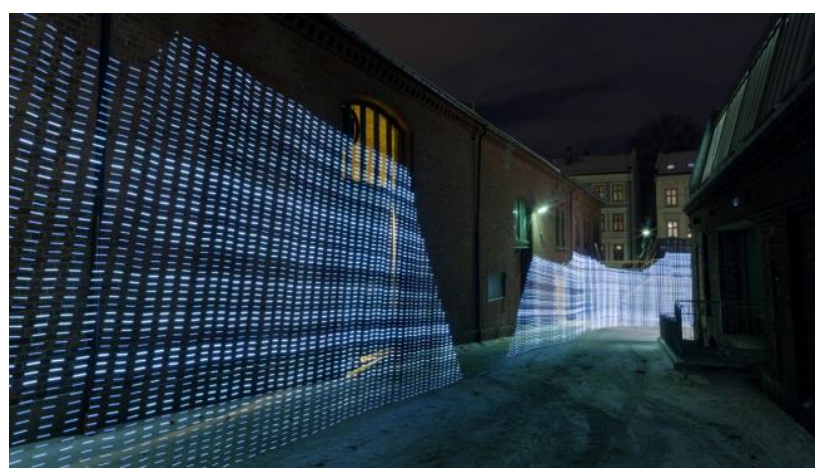

Figura 2: Immaterials: Light painting WiFi. O projeto investiga e contextualiza redes WiFi através de visualização fotográfica.

Realizado por Timo Arnall, Jørn Knutsen e Einar Sneve Martinussen, da Escola de Arquitetura e Design de Oslo. Fonte: Autor.

O fluxo de comunicação aumenta e passamos a ser responsáveis pelo que circula ao nosso redor. São novas formas de ver o espaço que nos rodeia, permeado de consumo, de valores, de ideologias, de informação privada imersa em espaço público.

Em "Do teto invisível" (2013), uma trama de centenas de metros de fibra ótica preenche o espaço aéreo de uma sala (CCBB-RJ, 2013) representando o espectro de interferências produzidas por sinais EMF de telefones celulares. As interferências detectadas pelo sensor de campos eletromagnéticos resultam na oscilações de cores e de intensidades de luz no espaço (através da conversão dos sinais em pulsos luminosos de um projetor de vídeo que "acende" os feixes de fibras óticas apontados para a sua lente). O sistema permite pressentir as intensidades das operações no ambiente onde se situa a instalação, pois se associa diretamente à visão do que se passa no nosso entorno.

Trata-se de um protótipo de um projeto que ambiciona algo mais que a representação de sinais invisíveis ao nosso olhar. É intenção de dar a uma obra a possibilidade de 'produzir' espaço e não apenas 'estar' no espaço. 


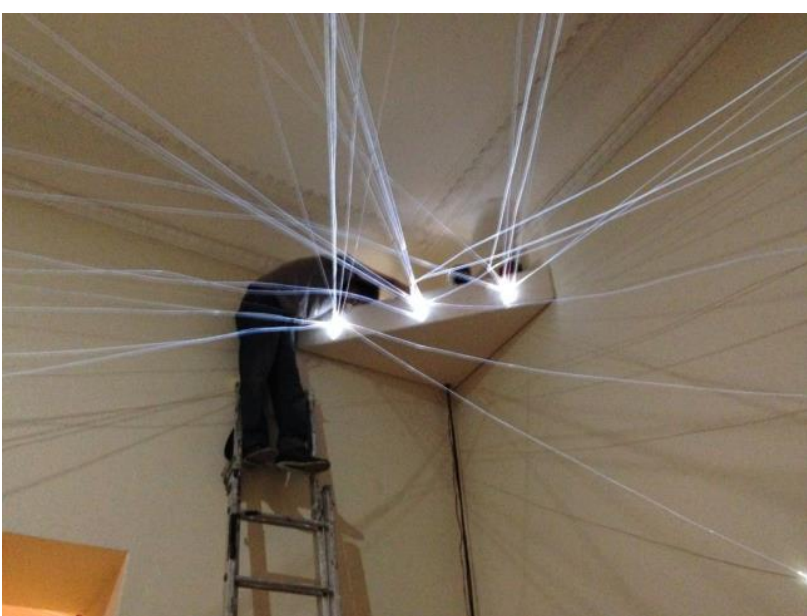

Figura 3: Montagem da instalação Do Teto Invisível no CCBB-RJ, 2013 [imagem do autor]

Tomando emprestada a base sociológica contida nas definições de uma obra site-specific, projetos como esse encontram companhia cada vez mais numerosa de autores, artistas, hackers, ativistas e pesquisadores de várias áreas, na intenção de fazer ver a política anexada aos fluxos de comunicação que nos escapam. As performances sonoras de Vanessa de Michellis, as Wi-fi Panoramas (antenas DIY) de Bengt Sjölén, Adam SomlaiFischer e Usman Haque, as caminhadas elétricas de Christina Kubisch, os Light Painting wi-fi do grupo Immaterials, as Spirit photographs (Digital Ethereal) de Luis Hernan são alguns exemplos de projetos nessa linha.

O próprio espaço social, agora hiper-conectado, já nos tem levado a repensar a natureza do lugar, em uma série de atualizações, passando por exemplo, pelas mídias locativas, como vem fazendo o artista Claudio Bueno em suas pesquisas e projetos artísticos, em especial quando nos indaga, "que lugar é esste?", sugerindo "um lugar difuso, de difícil circunscrição, que pode não estar somente aqui, nem lá, mas no lugar entre um e outro" (2010), talvez entre nós e as coisas, entre o que circula em torno de nossos corpos e reverbera no espaço.

Equacionando sentidos entre o que se vê e que se interpõe à visão ou entre o que se escuta e o que se percebe como ruído, há que se assumir que o sentido dessas obras pouco ortodoxas, é criado a partir do atrito de referências, em confluências de signos e cruzamento de sistemas.

Nesse campo ainda indefinido, haveria então toda uma "signagem" a ser (re)codificada em associação a esses projetos, em obras onde o sentido é criado a partir do atrito de referências, em confluências de signos, em busca de uma relação sinal-ruído que permita que tudo signifique, de forma expressiva, como queria o poeta e semioticista Decio Pignatari (1984), ao utilizar o termo signagem, para se referir a códigos icônicos e audiovisuais, que se diferenciariam dos códigos verbais ou 'linguagens' estabelecidas.

Motivado por questões análogas, na busca de expressividade entre sinal e ruído nas imagens, JeanPaul Fargier escreveu: "a escrita é então o que permite passar de uma poeira à outra (...) a visão da visão. Após termos visto o que eles não nos mostram, sabemos melhor o que é ver, vemos melhor o que é saber" (1993).

Pois bem, como "rami" em sala de cinema, como paisagem já permeada de fumaça, tornando mais opaco o campo de visão em modo contínuo, o que temos é talvez um fluxo que molda o espaço e aos poucos nos atinge, pelos mais variados meios de percepção.

Uma vez que vemos sempre com essa poeira nos olhos, que arranha 0 ato de ver, e por isso afeta mais diretamente a consciência do ruído, precisamos "saber melhor o que é ver, para vermos melhor o que é saber", parodiando a epígrefe de Jean Paul Fargier que abre este texto.

A quem, senão àqueles que flanam com os aparelhos sensórios em estado de alerta, caberia apontar essa fuligem que nos rodeia? Resta confiar em algo. Pois já assumimos que enxergar esse invisível, que constitui também o locus da política, é entender o constituinte primordial de um lugar ou espaço.

\section{REFERÊNCIAS}

Arendt, Hannah. (1991). A Vida do Espírito. Relume - Dumará. $22-25$

Argan, Giulio Carlo. (1992). Arte moderna: do iluminismo aos movimentos contemporâneos. Prefácio: Rodrigo Naves. São Paulo: Companhia das Letras. 271.

Bachelard, Gaston. (1989). A Poética do espaço. São Paulo: Martins Fontes.

Beiguelman, Giselle e LA FERLA, Jorge. (orgs) (2012). Nomadismos Tecnológicos. São Paulo: Ed. Senac.

Bruno, Fernanda. Contramanual para tecnologias smart: algoritmo, controle, tempo. Palestra no seminário A Vida Secreta dos Objetos, 2015, ainda não publicado.

Bueno, Claudio. Que lugar é esste?. (2010). 117 f. Dissertação (Mestrado em Poéticas Visuais) - ECA-USP, São Paulo. Disponível

http://www.teses.usp.br/teses/disponiveis/27/27159/tde10112010- 155909/pt-br.php. Acesso em 08 set. 2015.

Certeau, Michel de. (2000). A Invenção do Cotidiano, V1. Petrópolis: Ed. Vozes.

Deutsche, Rosalyn. (1986). Krzysztof Wodiczko's Homeless Projection and the Site of Urban Revitalization, Massachussets: The MIT Press, Vol. 38 October, 63-98.

Deutsche, Rosalyn. (2009). A arte de ser testemunha na esfera pública dos tempos de guerra, Rio de Janeiro: Concinnitas, volume 2, número 15, 174-183.

Fargier, Jean-Paul. (1993). Poeira nos Olhos. In: PARENTE, André (Org.). A imagem-máquina. Rio de Janeiro: Editora 34.

Flusser, Vilém. (1985). Filosofia da caixa preta - Ensaios para uma futura filosofia da fotografia. [S.I.: s.n.].

Foster, Hal. (1996). The return of the real: the avant-garde at the end of the century. London: The MIT Press.

Gibson, Todd. (2004). A Pilgrimage to The Lightning Field. From the Floor. http://fromthefloor.blogspot.com.br/2004/07/pilgrimage-tolightning-field-part-2.html Acesso em 06/09/2015

Kwon, Miwon. (2000). One Place After Another: Notes on Site Specificity. in: SUDERBURG, Erika (ed). Space, Site, Intervention: situating installation art. Minneapolis: University of Minnesota Press.

5 
Lippard, Lucy. (1997). The Lure of the Place. New York: New Press.

Manovich, Lev. (2013). Visualizing Social Photography. Software Studies.

http://lab.softwarestudies.com/2013/12/visualizing-socialphotography-new-mini.html Acesso em: 30 jul. 2015

Pignatari, Decio. (1984). Signagem da televisão. São Paulo: Editora Brasiliense.

Ranciere, Jacques. (2009). A Partilha do Sensível. São Paulo: Editora https://we.riseup.net/assets/164394/partilha\%20do\%20sensiv el\%20ranciere.pdf Acesso em: 10 jul. 2015

Steyerl, Hito. (2014). Proxy Politics: Signal and Noise E-Flux, New York.

http://www.e-flux.com/journal/proxy-politics Acesso em: 01 abr. 2015

Virilio, Paul. (1993). O Espaço Crítico. Rio de Janeiro: Editora 34. 55-80 